\title{
Composting of Wastes Produced in the Catalan Wine Industry
}

Teresa Gea ${ }^{(1)}$, Adriana Artola ${ }^{(1)}$, Xavier Sort ${ }^{(2)}$ and Antoni Sánchez $*^{(1)}$

(1) Escola Universitària Politècnica del Medi Ambient

Universitat Autònoma de Barcelona

Rbla Pompeu Fabra 1, 08100-Mollet del Vallès (Barcelona, Spain)

(2) Miguel Torres, S.A.

C/ Comerç 22, 08720-Vilafranca del Penedès (Barcelona, Spain)

*Corresponding Author: Dr. Antoni Sánchez

Escola Universitària Politècnica del Medi Ambient

Rbla Pompeu Fabra 1, 08100-Mollet del Vallès (Barcelona, Spain)

Tel.: (34) 935796784

Fax: (34) 935796785

E-mail: asanchez@eupma.uab.es 


\begin{abstract}
The wine industry in Catalonia (Spain) plays an important role in the economy of the region. In this framework, Miguel Torres S.A. is a well known industry specialized in the production of high-quality wines and brandy, which possesses its own vineyard. Two of the main solid wastes produced in this kind of industry are: stalk (waste from grape harvesting which is only produced during September and October) and wine sludge from the biological wastewater treatment plant which is steadily generated.

A composting process was proposed to treat these two organic wastes for recycling its organic matter content to the vineyard crops. Experiments at laboratory scale in static composting systems did not show positive results for different stalk:sludge mixtures due to the high moisture content of both wastes. Field composting experiments with windrow methods showed that the thermophilic range of composting could be achieved for a 2:1 stalk:sludge volumetric ratio resulting in a complete sanitation of the material with thermophilic temperature of over $55^{\circ} \mathrm{C}$ for 28 days. The stability and maturity of the final compost was very high (Dewar self-heating test maturity grade $\mathrm{V}$ and static respirometric index $0.10 \mathrm{mg} \mathrm{O} \cdot \mathrm{g}$ Total Organic Matter $\mathrm{r}^{-1} \cdot \mathrm{h}^{-1}$ ). Due to its seasonal production, stalk storage was necessary. A study of the changes of stalk properties during one year is also presented. Bulk density and water holding capacity decreased with storage time while FAS (Free Air Space) and porosity increased. No remarkable changes in organic matter content were observed.

Co-composting of stalk and wine sludge generated in the wine industry is presented as a sustainable waste management strategy, which produces a sanitized fertilizer suitable for application in the vineyard, closing the organic matter cycle.
\end{abstract}




\section{Introduction}

The wine industry in Catalonia, Spain, plays an important role in the economy of the region. Spain is a European leader in the innovations in the area. Large companies' investments have been characteristic in the last years, which have supposed the improvement of the quality of wines and spirits and the image of the cellars (Miguel Torres S.A., 2004). Miguel Torres S.A. (Vilafranca del Penedès, Barcelona, Spain) is a well known industry specialized in the production of high-quality wines and brandy. During the production process significant amounts of liquid and solid wastes are generated. Miguel Torres has a wastewater treatment plant in its facilities for the treatment of wastewater and vinasse generated in the industry. Approximately, $80 \%$ of the total wastes generated are organic wastes or by-products. The characteristic of the wastes produced in Miguel Torres are grape pomace (50\%), lees (20\%), stalk (7.6\%) and dewatered wine sludge from the wastewater treatment plant $(7 \%)$. Recycling of grape pomace (grape peels and seeds) which is produced during the grape pressing, and lees, consisting of the sediments from the fermentation and the clarification operations, is already well established. The management of the other two important organic solid wastes, stalk and wine sludge, is at the moment ordered to an external company.

At present, there is a tendency towards the agricultural use of sludge. The unique legal restriction to direct land application of the sludge is given by its content on heavy metals and potentially toxic compounds. Therefore "clean" sludges coming from agricultural industries may be suitable for direct land application. Miguel Torres possesses its own vineyard in Spain, California and Chile. Given that Spanish soils are poor in organic matter, vineyard crops require organic fertilization. However, European Commission is preparing a new Directive on the biological treatment of organic wastes (European Commission, 2001). According to this Directive the sanitation of sludge 
before its application to land will be mandatory. The absence of pathogen microorganisms is also crucial in the vineyard cultivation. Composting is one of the alternatives proposed by the Directive in order to achieve sludge sanitation.

Main factors influencing the composting process are temperature, water content, oxygen concentration in the composting matrix, porosity and free air space (FAS). Temperature is both a consequence of the composting process (microbial metabolism) and a control parameter. Temperatures providing the maximum degradation velocity are in the range of $40-70^{\circ} \mathrm{C}$ (Haug 1993). The water content of sewage sludge is usually too high for direct composting and a bulking agent is necessary to reach an optimum water content, porosity and FAS (Haug 1993). The optimization of the sludge-bulking agent mixtures for urban or industrial sludge composting has been extensively studied (Miner et al. 2001; Milne et al. 1998; Morisaki et al. 1989; Sesay et al. 1997). Also, the type of bulking agent used and its particle size has been empathized as an important factor in sludge composting (Jokela et al. 1997; Morisaki et al. 1989). Studies on sludge composting are presented at different scales, laboratory, pilot plant or field scale (Jokela et al. 1997; Sesay et al. 1997), being the temperature profile the main difference observed at the studied scales. Obviously, the amount of heat generated and the heat retention capacity of the material increase as the mass of the material increases.

Stalk appears to be an ideal bulking agent for sludge composting, due to physical properties such as porosity (provided by its branch-type structure) and resistance to biodegradation of the hard-wood fraction (Tuomela et al. 2000). Its chemical properties are also optimal. Stalk $\mathrm{C} / \mathrm{N}$ ratio is high (around 39) and equilibrates the low $\mathrm{C} / \mathrm{N}$ ratio of sludge (around 5). Co-composting wine sludge from the wastewater treatment plant with stalk as bulking agent would generate a stabilized fertilizer suitable for its application to the vineyard crops. Moreover the composting process allows treating 
different wood wastes that are generated sporadically in the wine industry, such as ground old oak barrels (Bertrán 2004).

Wine sludge from the wastewater treatment plant is generated steadily during the year and stalk is yearly produced during the grape harvest, a short period of 4-6 weeks around September. Stalk storage is necessary to use it in wine sludge composting during the rest of the year.

The objectives of this work are: i) to study the co-compostability of stalk with wine sludge to ensure a complete sanitation of the material, ii) to determine the stability and maturity of the final compost and iii) to monitor the properties of ground stalk during the storage time to study their influence on the optimum ground stalk:sludge volumetric ratio for composting.

\section{Materials and methods}

\section{Materials}

The waste materials studied were dewatered (by centrifugation) wine sludge from Miguel Torres wastewater treatment plant; and stalk from the wine production process after grape harvest. Wine sludge is steadily generated during the year and was sampled just after dewatering. Stalk is generated only during the grape harvest in September and October. Stalk was ground to $5 \mathrm{~cm}$ after the grape harvest and stored in a pile in the open air. These materials were monthly sampled for analysis. Composting experiments were carried out during the year following the grape harvest in September.

Pine wood chips were used as alternative bulking agent. Sawdust was used as drying agent. Both materials were obtained from a local carpentry. 


\section{Composting experiments}

Laboratory-scale experiments were undertaken using 4.5-L Dewar® vessels conditioned for static composting providing a stopper and placing a rigid wire net near the bottom to separate the material from possible leachates. The stopper was perforated in three points for temperature and oxygen content monitoring and air supply. Wine sludge and stalk were used in the laboratory-scale experiments mixed in different volumetric ratios. In some experiments, wood chips were used as an alternative bulking agent, whereas sawdust was used as absorbent material to decrease the moisture content of the wine sludge. A complete description of the composting Dewar vessel can be found in Gea et al. (2003).

Field scale composting experiments were carried out under real conditions in Miguel Torres facilities using a dynamic windrow composting system. Two composting piles of approximately $150 \mathrm{~m}^{3}$ (height: $2 \mathrm{~m}$, width: $3 \mathrm{~m}$ ) were built. The volumetric ratios (stalk:sludge) of the piles were 1:1 and 2:1 for Pile 1 and 2, respectively. Initial mixing and pile turnings were performed using a front end loader. Pile turning was performed weekly during the composting experiment. The piles were not covered and situated on a concrete floor to collect the possible leachates generated in the process. Temperature and interstitial oxygen of the piles were routinely monitored.

\section{Oxygen, aeration control and temperature monitoring}

Laboratory scale: Air was supplied to the vessels in aeration cycles where the total time of the cycle, aeration time and air flow were programmed and changed on the basis of the measured oxygen concentration, to ensure an oxygen concentration over 10\%. Pt-100 sensors were used for temperature monitoring connected to a data acquisition system (DAS-8000, Desin, Spain) which was connected to a standard PC. 
The system allowed, by means of the proper software (Proasis ${ }^{\circledR}$ Das-Win 2.1, Desin, Spain), the continuous on-line visualisation and registration of temperature. Pt-100 sensors were placed in the material to measure temperature at half of the height of the material in the Dewar vessel.

Field Scale: Temperature was measured with a portable Pt-100 sensor (Delta Ohm HD9214) at two different depths of pile, 40 and $90 \mathrm{~cm}$, in at least 7 different points. Temperature values are presented as average values.

Oxygen concentration in interstitial air was measured with a portable $\mathrm{O}_{2}$ detector (Oxy-ToxiRAE, RAE) connected to a portable aspiration pump, both in laboratory and field experiments. Oxygen and temperature were measured at the same points in the field scale experiments.

\section{Respirometric tests}

A static respirometer was built according to the original model described previously by Ianotti et al. (1993) and following the modifications and recommendations given by the U.S. Department of Agriculture and U.S. Composting Council (2001). Approximately $250 \mathrm{~mL}$ of a compost sample were placed in a $500 \mathrm{~mL}$ Erlenmeyer flask on a nylon mesh screen that allowed air movement under and through the solid sample. The setup included a water bath to maintain the temperature at $37^{\circ} \mathrm{C}$ during the respirometric test. Prior to the assays, samples were incubated for 18 hours at $37^{\circ} \mathrm{C}$. During all the incubation period samples were aerated with previously humidified air at the sample temperature. The drop of oxygen content in the flask containing the compost sample was monitored with an oxygen meter (Lutron 5510, Lutron Co. Ltd., Taiwan) connected to a personal computer (RS232 communication protocol) with a proper software to register the oxygen values. The rate of respiration of a compost 
sample based on total organic matter content (TOM) was then calculated from the slope of oxygen level decrease according to the standard procedures (U.S. Department of Agriculture and U.S. Composting Council, 2001). Results of the static respirometric index (SRI) referred to total organic matter content are presented as an average of three replicates.

\section{Germination tests}

Relative Germination Rate and Relative Root Elongation of cucumber seeds were determined from a compost extract following the method 05.05-B 'In-Vitro Germination and Root Elongation' proposed by TMECC (Test Methods for the Examination of Composting and Compost, U.S. Department of Agriculture and U.S. Composting Council 2001).

\section{Analytical methods}

Different parameters were determined according to the standard procedures recommended by TMECC (Test Methods for the Examination of Composting and Compost, U.S. Department of Agriculture and U.S. Composting Council 2001) as follows: water and dry matter content were determined with the method 03.09-A 'Total Solids and Moisture at $70 \pm 5^{\circ} \mathrm{C}^{\prime}$, total organic matter (TOM) content with the method 05.07-A 'Loss On Ignition Method', bulk density, free air space (FAS), pore space (PS), water holding capacity (WHC) with the method 03.01-A 'Quick-Test for Bulk Density, Porosity/Pore Space, Free Airspace and Water-Holding Capacity of Compost', and Dewar self-heating maturation test with the method 05.08-D 'Dewar Self-Heating Test'. 


\section{Results and discussion}

\section{Evolution of material properties}

Figures 1 and 2 show the evolution of water and organic matter content of the materials under study. Wine sludge obtained after centrifugation in the wastewater treatment plant presented a high water content (average value 88\%), and an average organic matter content of $70 \%$. Ground stalk, stored outdoors, presented high water content $(60-80 \%)$ due to the rainfall in winter and spring and the humidity of the area. Consequently, water content within the recommended range of 40-60\% (Haug 1993; Saña and Soliva 1987) could not be achieved by mixing the two materials. Therefore it was decided to cover a part of the ground stalk storage pile to prevent the contact of the material with water from rainfall (covered stalk). As Figure 1 shows, this strategy produced an important reduction of the stalk water content.

Additionally, it has to be pointed that although certain biodegradation took place during storage time, leading to physical and structural changes that could be visually recognized, no significant reduction of the total organic matter content was observed in stalk when increasing the storage time (Figure 2). This was due to the fact that stalk is composed mainly by branches (hard-wood fraction) and the biodegradation only takes place in the soft-wood fraction which is a minor fraction of stalk (Tuomela et al. 2000). Wine sludge composition, on the other hand, presented steady values of water and organic matter content during the period of study.

Figure 3 shows the reduction of bulk density and water holding capacity and the increase of FAS and porosity during stalk storage time. This was the result of the biodegradation of the soft-wood fraction of stalk, which consisted of small size particles that filled the void spaces in the structure of the branches. The reduction in stalk bulk density (or FAS increase) can make more difficult the integration with wine sludge 
when acting as bulking agent. The water holding capacity of stalk also decreases with time and thus the capacity of absorbing excess water from the wine sludge. Consequently an increment of the stalk:sludge volumetric ratio required for composting was expected for long storage times. This fact will probably result in an excessive FAS in the final mixture (Haug 1993).

\section{Composting experiences at laboratory scale}

To evaluate the composting potential of the wastes under study, different ground stalk:sludge mixtures with volumetric ratios of $1: 1,2: 1$ and $3: 1$ were tested in $4.5-\mathrm{L}$ composting vessels. Experiments were undertaken at different dates during the monitored period of stalk storage. Table 1 shows the initial water content and the maximum temperature reached in these experiments. Due to the high water content of the original materials, the mixtures resulted in water contents within $75-80 \%$ which were higher than those considered as optimal (Haug 1993). The mixtures presented poor activity and only in a few cases temperatures over $40^{\circ} \mathrm{C}$ were reached. None of the experiments reached the thermophilic range of temperatures (over $45^{\circ} \mathrm{C}$ ) necessary to obtain a sanitized material suitable for land application (European Commission, 2001). Figure 4 shows the temperature profile obtained for three of the mixtures tested.

When the stored stalk was covered, its water content was reduced to about $20 \%$ (Figure 1). Different experiments were carried out with covered stalk and other alternative bulking agents such as wood chips, but the resulting mixtures again presented an excessive water content and the material did not reach temperatures above $40^{\circ} \mathrm{C}$ (Table 2).

Since the studied wine sludge was dewatered by centrifugation, one possible strategy to reduce water content in the centrifugation operation might be the addition of 
polyelectrolyte to the wine sludge. To simulate this, sawdust was added to wine sludge as an absorbent of moisture before mixing with stalk. This strategy improved the results of the composting process. The temperature reached values near $50^{\circ} \mathrm{C}$ and the thermophilic range was retained for 3.5 days, as can be seen in Figure 5. Adding sawdust in moderate amounts had a positive effect in the composting process because sawdust absorbed excess water from the wine sludge, although the reduction in the total water content of the mixture was low $(75.5 \%$, Table 2$)$. Moreover, sawdust produced a very homogeneous mixture with wine sludge breaking the typical aggregated structure of a dewatered sludge and improving its integration with stalk by reducing the size of aggregates. This effect was mainly due to the small particle size of sawdust.

\section{Field experiments}

Piles 1 and 2 (stalk:sludge volumetric ratios of 1:1 and 2:1, respectively) were built during the grape harvest period (September) and monitored during the composting process. Due to the high water content of the fresh stalk, the water content of the initial mixtures of both piles was high, $81 \%$ for Pile 1 and $75 \%$ for Pile 2 . In Pile 1 , the material practically had no porosity and consequently temperature did not reach the thermophilic range, remaining under $40^{\circ} \mathrm{C}$ (data not shown) and it was decided to stop the composting experiment after two weeks. On the other hand, in Pile 2 the composting process reached average temperatures over $50^{\circ} \mathrm{C}$ in one week and over $60^{\circ} \mathrm{C}$ in two weeks (Figure 6). Values of temperatures over $55^{\circ} \mathrm{C}$ were measured for 4 weeks (days 14-42). As pile turnings were carried out once a week, it can be concluded that the totality of the material was exposed to temperatures in the thermophilic range. Besides, according to U.S. Environmental Protection Agency Rule 503, total sanitation of biosolids is obtained at $55^{\circ} \mathrm{C}$ for 15 days and turned 5 times, which was the case of wine 
sludge composting (U.S. Environmental Protection Agency 1995). On the other hand, aerobic conditions were maintained in the first layer of the pile (40 $\mathrm{cm} \mathrm{depth})$, but oxygen content dropped under $8 \%$ when approaching the center of the pile $(90 \mathrm{~cm})$. Because of water evaporation due to the high temperatures reached, the water content of Pile 2 was reduced from 75 to $68 \%$ in 11 days in spite of the rainfall. However, values of moisture in Pile 2 were always in the high range of the composting process (average value of $70 \%)$.

On the other hand, other monitored parameters correlated well with those found in traditional biosolids composting (Haug 1993). For instance, total organic matter content decreased from an initial value of $77 \%$ to a final value of $63 \%$, whereas $\mathrm{pH}$ value ranged from 8.2 to 9.3 . Finally, an important reduction of total volume was observed in a percentage of $43 \%$ in a total composting period of 120 days.

The excellent results obtained for Pile 2 contrast with the laboratory scale experiments carried out with the same volumetric ratio 2:1 (Figure 4, Table 1) where the thermophilic range was not achieved. As mentioned before, the water content and the FAS of the mixture were critical for the proper composting development. However, in large scale experiments the thermal inertia of the material compensated the problems presented with FAS and excess of water. Furthermore, frequent turning of the material contributed to the complete higienization of the material and to the disintegration of stalk.

In addition to stalk:sludge volumetric ratio, bulking agent particle size and operation scale are interrelated and can affect the composting process in the same order of magnitude (Gea et al. 2003). The particle size of ground stalk $(5 \mathrm{~cm})$ may result too big for composting in $4.5 \mathrm{~L}$ vessels. On the other hand, as the bulk density of stalk decreased within the storage time, the amount of stalk required for adjusting the 
properties of the mixture with wine sludge (i.e. water content) increased, leading to high requirements of bulking agent volumetric ratio and to an excessive FAS. This excess of FAS can be reduced when operating at higher scales because of the compaction phenomena of the composting material (McCartney and Chen 2001). Moreover, the bigger the organic matrix is, the higher heat generation and retention occurs, which may improve the temperature profiles obtained (Sherman-Huntoon 2000). On the other hand, open dynamic systems such as turned piles produce higher losses of water by evaporation due to the high surface area available.

\section{Final compost properties}

One of the most important characteristics to determine in sludge compost intended for vineyard application is the stability and the maturity of the material obtained. Therefore, the Dewar self-heating test and the respirometric index were measured for the compost obtained. These tests are popularly used in predicting compost stability and maturation (Weppen, 2002; Adani et al., 2003) and are recommended in standard procedures and regulations (U.S. Department of Agriculture and U.S. Composting Council, 2001; European Commission, 2001). Static respirometric index (SRI) obtained was $0.10 \pm 0.02 \mathrm{mg} \mathrm{O}_{2} \cdot \mathrm{g} \mathrm{TOM}^{-1} \cdot \mathrm{h}^{-1}$, which can be classified in the range of highly stable materials (California Compost Quality Council, 2001). Also, the Dewar self-heating test resulted in the maximum maturity grade (V) with temperature increments below $2^{\circ} \mathrm{C}$.

Finally, the germination indexes obtained for the final compost were $90 \%$ and $100 \%$ for the Relative Root Elongation and the Relative Germination Rate, respectively. These indexes indicated that there was no evidence of the presence of plant toxic compounds. 


\section{Conclusions}

From this work, it can be concluded that: 1) Bulk density and water holding capacity of stalk decrease during the storage time as biodegradation of soft-wood fraction takes place, while FAS and porosity increase. Thus, the optimum volumetric ratio of stalk:sludge for composting should be increased during the year. 2) High water content of stalk and wine sludge was the main problem in the composting process studied under laboratory scale conditions. The addition of some adsorbent material or the improvement of the dewatering system are the two strategies proposed to reduce the water content. 3) At field scale, a highly stable and mature final compost was obtained when a 2:1 stalk:sludge volumetric ratio was used. Windrow composting with frequent turning appear to be an optimal technology for the composting of this waste from the wine industry.

In conclusion, co-composting of stalk and wine sludge generated in the wine industry is presented as a sustainable waste management strategy, which produces a sanitized fertilizer for application in the vineyard, closing the organic matter cycle.

\section{Acknowledgements}

The authors wish to thank the financial support provided by the Spanish Ministerio de Ciencia y Tecnología (Project REN2003-00823) and Miguel Torres S.A.

\section{References}

Adani, F., Gigliotti, G., Valentini, F. and R. Laraida. 2003. Respiration index determination: a comparative study of different methods. Compost Sci. Util., $11: 144-151$. 
Bertrán, E., Sort, X., Soliva, M. and I. Trillas. 2004. Composting winery waste:sludges and grape stalks. Bioresource Technol., 95:203-208.

California Compost Quality Council. 2001. CCQC-Compost Maturity Index. Available: http://www.ccqc.org/Documents/MatIndex.pdf [2002, October 10].

European Commission. 2001. Working document. Biological treatment of biowaste. $2^{\text {nd }}$ draft. Available: http://europa.eu.int/comm/environtment/waste/facts_en.htm [2001, February 12].

Gea, M.T., Artola, A. and A. Sánchez. 2003. Application of experimental design technique to the optimization of bench-scale composting conditions of municipal raw sludge. Compost Sci. Util., 11:321-329.

Haug, R.T. 1993. The Practical Handbook of Compost Engineering. Lewis Publishers. Boca Raton, Florida.

Ianotti, D.A., Pang, T., Toth, B.L., Elwell, D.L., Keener, H.M. and H.A.J. Hoitink. 1993. A quantitative respirometric method for monitoring compost stability. Compost Sci. Util., 24:52-65.

Jokela, J., Rintala, J., Oikari, A., Reinikainen, O., Mutua, K. and T. Nyrönen. 1997. Aerobic composting and anaerobic digestion of pulp and paper mill sludges. Wat. Sci. Technol., 36:181-188.

McCartney, D. and H. Chen. 2001. Using a Biocell to measure effect of compressive settlement on Free Air Space and microbial activity in windrow composting. Compost Sci. Util., 9:285-302.

Miguel Torres S.A. 2004. Nuestros vinos: Cataluña, Vino y Cultura. Available: http://www.torres.es/esp/asp/nv_catalunya.asp [2004, October 14]. 
Milne, B.J., Baheri, H.R. and G.A. Hill. 1998. Composting of a heavy oil refinery sludge. Environ. Prog., 17:24-27.

Miner, F.D., Koeing, R.T. and B.E. Miller. 2001. The influence of bulking material type and volume on in-house composting in high-rise, caged layer facilities. Compost Sci. Util., 9:50-59.

Morisaki, N., Phae, C.H., Nakasaki, K., Shoda, M. and H. Kubota. 1989. Nitrogen transformation during thermophilic composting. J. Ferm. Bioeng., 67:57-61 .

Saña, J. and M. Soliva. 1987. Composting. Process, systems and applications (original in Spanish). Servei de Medi Ambient, Diputació de Barcelona, Barcelona, Spain.

Sesay, A.A., Lasaridi, K., Stentiford, E. and T. Budd. 1997. Controlled composting of paper pulp sludge using the aerated static pile method. Compost Sci. Util., 5:8296.

Sherman-Huntoon, R. 2000. Latest developments in mid-to-large-scale vermicomposting. Biocycle, 41:51-54.

Tuomela, M., Vikman, M., Hatakka, A. and M. Itavaara. 2000. Biodegradation of lignin in a compost environment: a review. Bioresource Technol., 72:169-183.

U.S. Department of Agriculture and U.S. Composting Council. 2001. Test methods for the examination of composting and compost. Edaphos International, Houston, TX.

U.S. Environmental Protection Agency. 1995. A Guide to the Biosolids Risk Assessments for the EPA Part 503 Rule. Available: http://www.epa.gov/owm/mtb/biosolids/503rule/ [2004, October 14].

Weppen, P. 2002. Determining compost maturity: evaluation of analytical properties. Compost Sci. Util., 10:6-15. 


\section{Tables}

Table 1. Initial water content and maximum temperature achieved in laboratory scale composting experiments with different mixtures stalk/sludge.

\begin{tabular}{ccccc}
\hline \multirow{2}{*}{ Date } & \multicolumn{2}{l}{ Volumetric Ratio } & $\begin{array}{c}\text { Initial Water Content } \\
(\%)\end{array}$ & $\begin{array}{c}\text { Maximum Temperature } \\
\left({ }^{\circ} \mathrm{C}\right)\end{array}$ \\
\cline { 2 - 4 } & Stalk & Sludge & 83.1 & 46.5 \\
\hline 17Sept & 1 & 1 & 83.2 & 39.1 \\
\hline 17Sept & 1.5 & 1 & 82.1 & 43.9 \\
\hline 17Sept & 2 & 1 & 82.0 & 38.9 \\
\hline 17Sept & 2.5 & 1 & 81.9 & 42.9 \\
\hline 17Sept & 3 & 1 & 83.2 & 30.3 \\
\hline 3Oct & 1 & 1 & 79.3 & 38.1 \\
\hline 3Oct & 2 & 1 & 76.8 & 36.7 \\
\hline 3Oct & 3 & 1 & 83.6 & 34.0 \\
\hline 17Oct & 2 & 1 & 80.5 & 30.5 \\
\hline 17Oct & 3 & 1 & 83.4 & 29.4 \\
\hline 14Nov & 2 & 1 & 80.8 & 31.2 \\
\hline 14Nov & 3 & 1 & 83.3 & 27.7 \\
\hline 16Jan & 1 & 1 & 73.2 & 38.5 \\
\hline 13Feb & 2 & 1 & & \\
\hline
\end{tabular}


Table 2. Initial water content and maximum temperature reached in laboratory scale composting experiments using an alternative bulking agent and amendment.

\begin{tabular}{|c|c|c|c|c|c|c|c|}
\hline \multirow{2}{*}{ Date } & \multicolumn{5}{|c|}{ Volumetric Ratio } & \multirow{2}{*}{$\begin{array}{l}\text { Initial Water } \\
\text { Content }(\%)\end{array}$} & \multirow{2}{*}{$\begin{array}{c}\text { Maximum } \\
\text { Temperature }\left({ }^{\circ} \mathrm{C}\right)\end{array}$} \\
\hline & Stalk & Covered stalk & Wood Chips & Sawdust & Sludge & & \\
\hline $14 \mathrm{Nov}$ & 0 & 0 & 1 & 0 & 1 & 76.6 & 38.6 \\
\hline 16Jan & 1 & 0 & 0 & 1 & 1 & 82.2 & 27.9 \\
\hline $6 \mathrm{Feb}$ & 0 & 0 & 1 & 0 & 1 & 80.2 & 32.5 \\
\hline $6 \mathrm{Feb}$ & 0 & 1 & 0 & 0 & 1 & 79.8 & 37.7 \\
\hline $13 \mathrm{Feb}$ & 1 & 0 & 0 & 1 & 1 & 70.5 & 38.7 \\
\hline $13 \mathrm{Feb}$ & 0 & 0 & 1 & 1 & 1 & 68.6 & 44.2 \\
\hline $24 \mathrm{Feb}$ & 1 & 0 & 0 & 3 & 3 & 73.3 & 49.5 \\
\hline $24 \mathrm{Feb}$ & 1 & 0 & 0 & 6 & 3 & 70.6 & 38.8 \\
\hline 6Mar & 0 & 2 & 0 & 0 & 1 & 77.6 & 33.3 \\
\hline $6 \mathrm{Mar}$ & 0 & 3 & 0 & 0 & 1 & 77.1 & 36.4 \\
\hline $6 \mathrm{Mar}$ & 0 & 6 & 0 & 1 & 3 & 75.5 & 28.0 \\
\hline $6 \mathrm{Mar}$ & 0 & 8 & 0 & 1 & 4 & 70.8 & 31.9 \\
\hline
\end{tabular}




\section{Legend to figures}

Figure 1. Water content evolution of the materials under study: stalk (circle), covered stalk (triangle) and wine sludge (square). Time scale (in months) ranges from September (grape collection) to the end of the study.

Figure 2. Total Organic Matter content evolution of the materials under study: stalk (circle), covered stalk (triangle) and wine sludge (square). Time scale (in months) ranges from September (grape collection) to the end of the study.

Figure 3. Evolution of physical properties of stalk during storage time: Bulk density $\left(\mathrm{kg} / \mathrm{m}^{3}\right)$ (circle), Pore Space $(\%)$ (triangle), Free Air Space (\%) (square) and Water Holding Capacity (\% volume basis) (diamond). Time scale (in months) ranges from September (grape collection) to the end of the study.

Figure 4. Example of temperature profiles obtained for three stalk and sludge mixtures in different dates and for different stalk:sludge volumetric ratios: $17 \mathrm{Sept} / 3: 1$ (solid line), 17 Sept/2:1 (dotted line), 17 Sept/1:1 (dashed-dotted line), room temperature (dashed line).

Figure 5. Temperature profile for the mixture stalk:sawdust:sludge in 6:1:3 volumetric ratio: composting temperature (solid line) and room temperature (dotted line).

Figure 6. Temperature and oxygen profiles for the field experiment with 2:1 (stalk:sludge) volumetric ratio: composting temperature (circle), oxygen (square) and pile turning (triangle). 
Fig 1; Gea et al

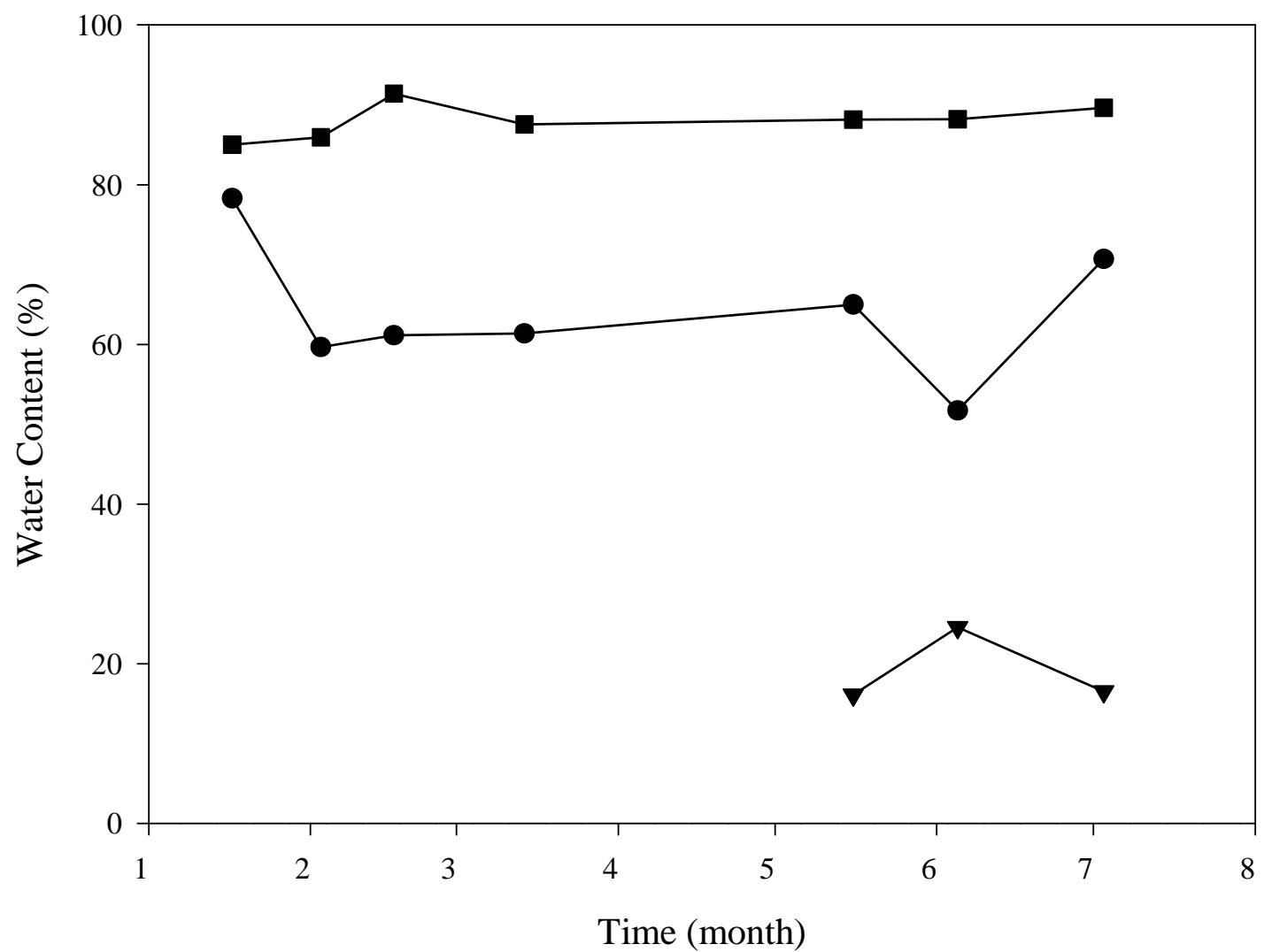

Time (month) 
Fig 2; Gea et al

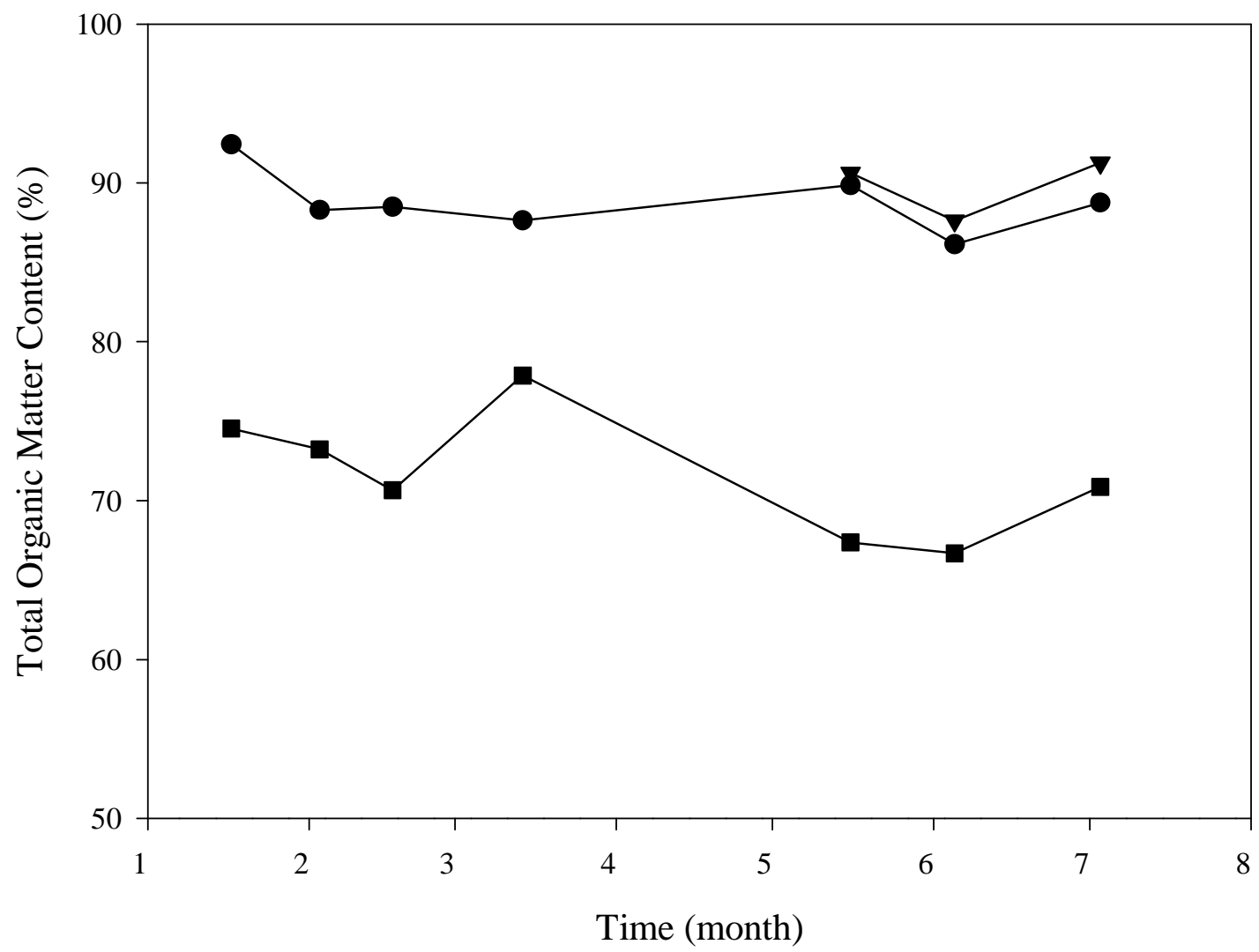


Fig 3; Gea et al

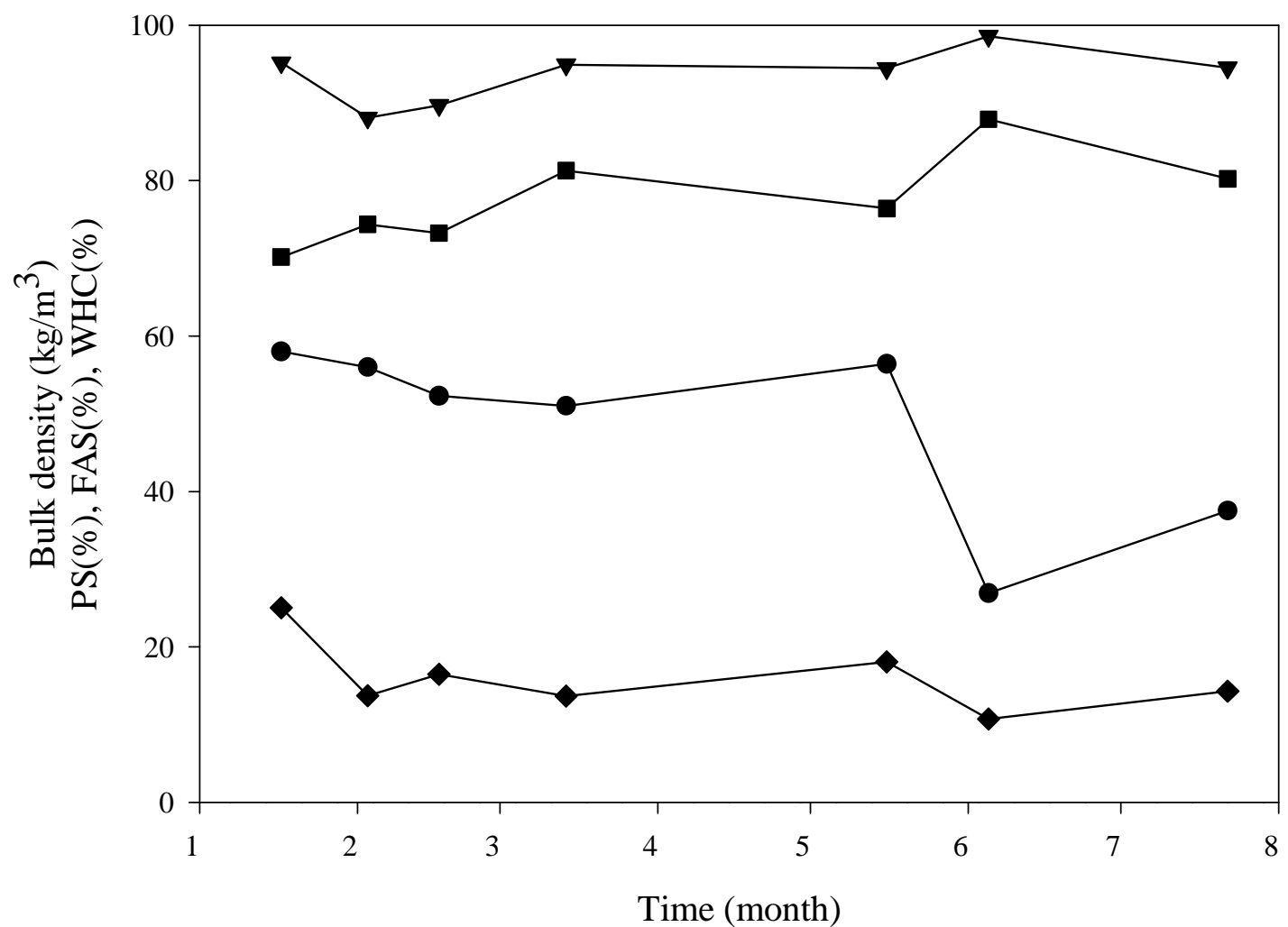


Fig 4; Gea et al

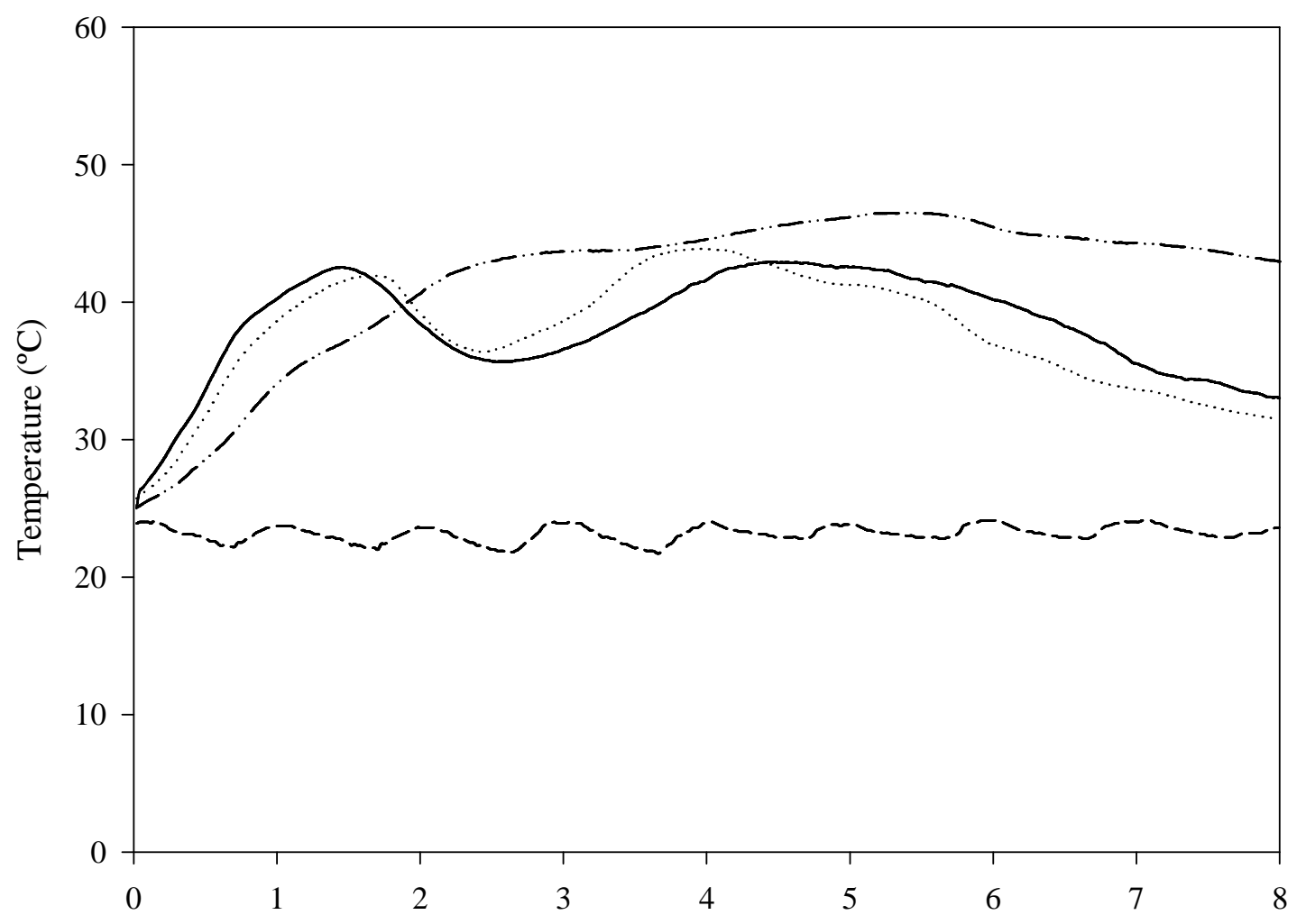

Time (d) 
Fig 5; Gea et al

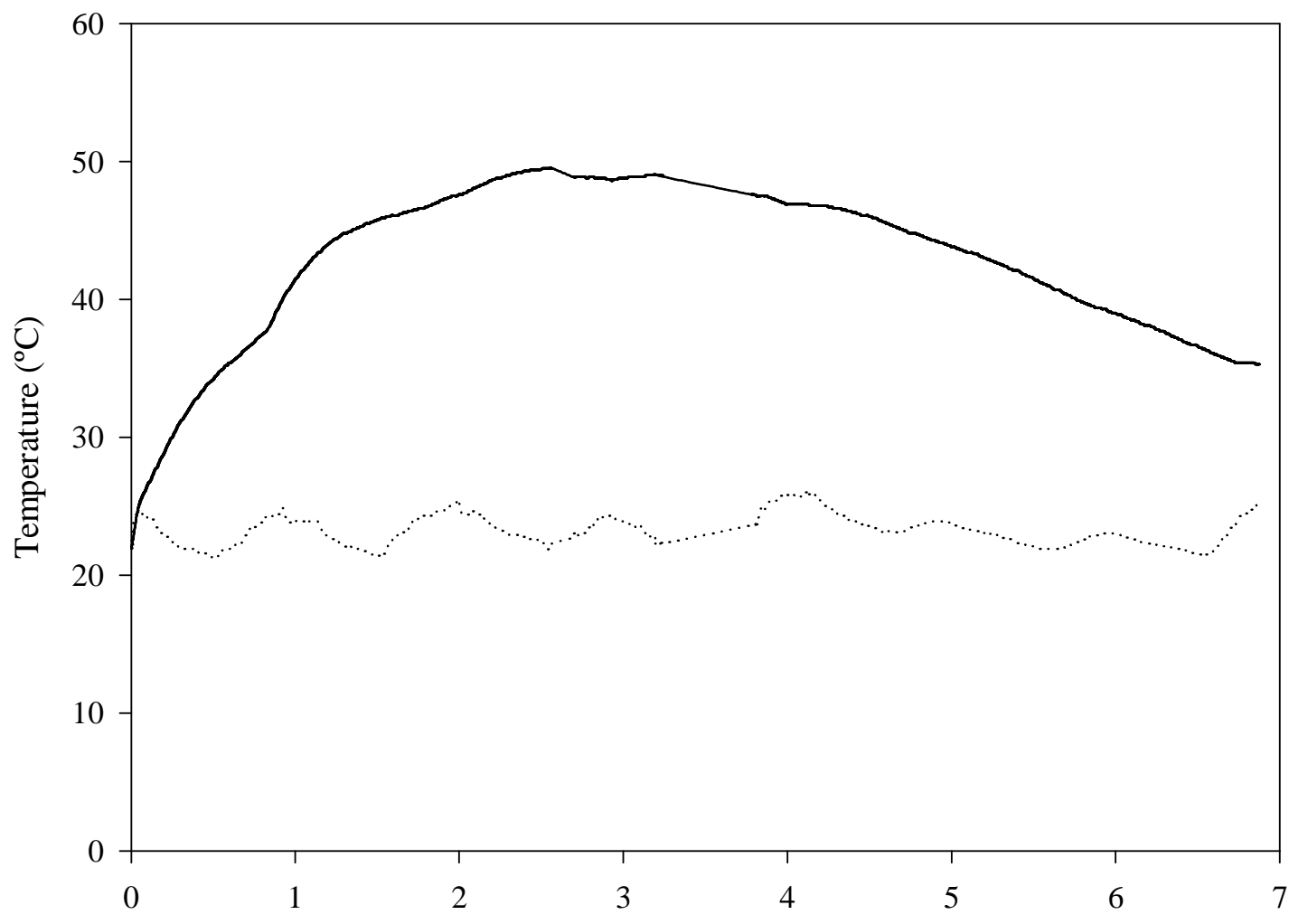

Time (d) 
Fig 6; Gea et al

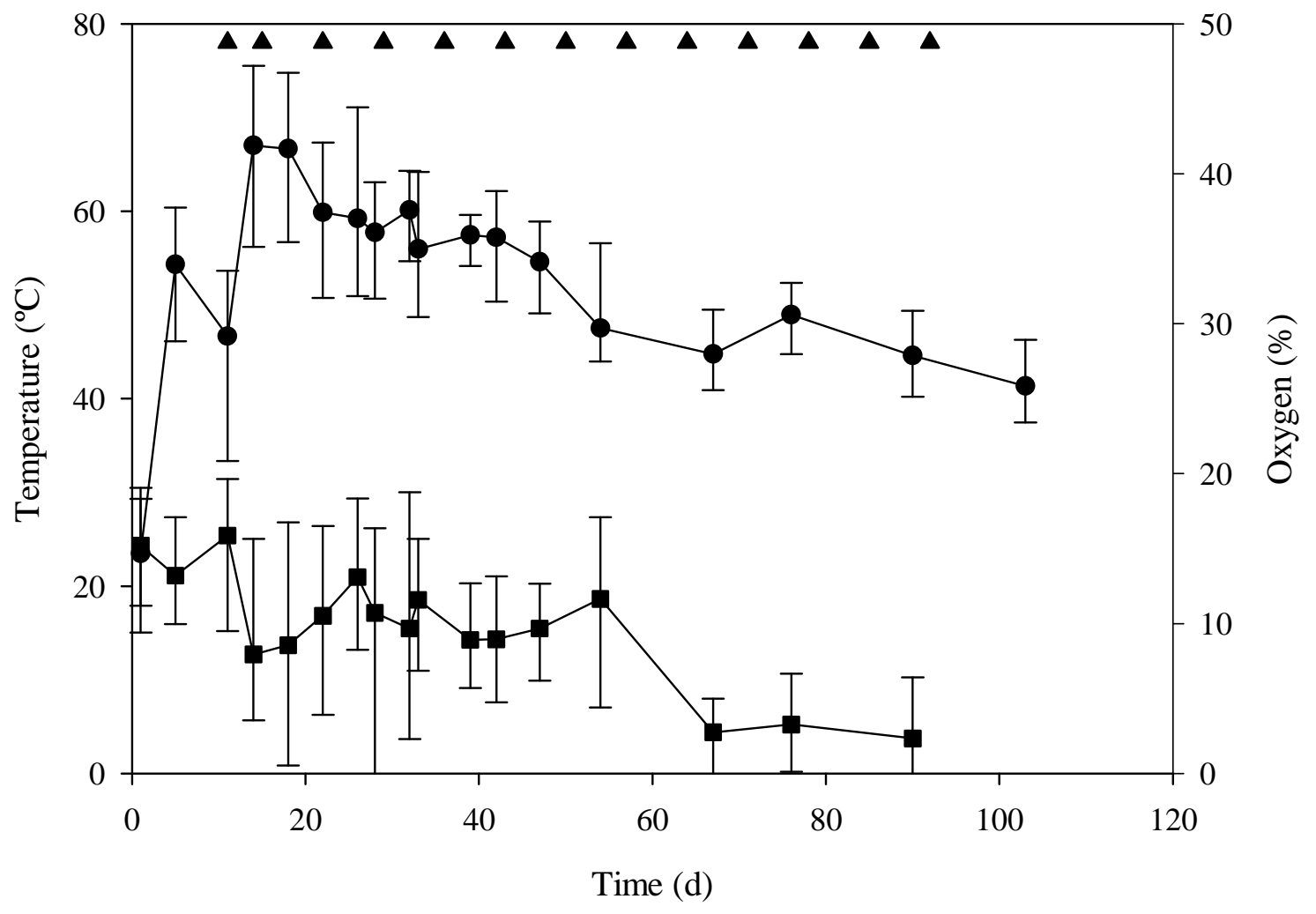

